\title{
Determining Single Point Percentage Daylight Factor (\%DF) Values through Field Work Data in Malaysia
}

\author{
Sharifah Fairuz Syed Fadzil, Adel Abdullah
}

\begin{abstract}
This paper suggests a way to measure \%DF using fieldwork data by taking samples in residential rooms at the University Science Malaysia. The two rooms face east and west for comparison. Two varied window to wall (WWR) and window to floor (WFR) ratios were tested for this experiment. The \%DF values calculated from this research were analysed by comparing the east-facing room to the west-facing room and by comparing the different WWR and WFR. The results indicate that given the dynamic and varying sky conditions, east-facing rooms resulted in higher \%DF values in both WWR and WFR. It is also found that in Malaysian skies, a 1\%DF value is a good estimate for a residential room natural illumination level.
\end{abstract}

Keywords - Daylight factor \%DF, Window to wall ratio (WWR), Window to floor ratio (WFR)

\section{Introduction}

The most popular and commonly used formula to measure and analyse day lighting performance in buildings is the percentage daylight factor. The daylight factor concept is relatively simple. It was introduced by Trotter in 1895 [1] and has been used ever since. The daylight factor quantifies daylight levels and distribution patterns in a building's interior spaces. The formula assumes overcast skies and does not consider excessive illumination caused by direct sunlight penetration.

The formula for $\% \mathrm{DF}$ is derived as follows:

$$
\% \mathrm{DF}=\mathrm{Ei} / \mathrm{Eo} \mathrm{X} 100 \%
$$

whereby Ei is the illuminance due to daylight at a point on the indoors working plane, and Eo is the simultaneous outdoor illuminance on a horizontal plane from an unobstructed hemisphere of an overcast sky [2] [3] [4] [5].

By using relative values that compare indoor to outdoor illuminance, this factor is constant under widely varying outdoor sky and day lighting conditions [6]. Worldwide design guidelines currently recommend daylight provision in terms of the long established DF [7].

Sharifah Fairuz Syed Fadzil

School of Housing, Buildings and Planning (HBP)

Universiti Sains Malaysia (USM)

Malaysia

Adel Abdullah

School of Housing, Buildings and Planning (HBP)

Universiti Sains Malaysia (USM)

Malaysia
Real sky conditions vary throughout the world depending on the location, climate and sun path, but generally, skies can be divided into three categories [8]:

- Clear skies

- Cloudy and partly cloudy skies

- Overcast skies

Realistically, there is no natural sky that is uniformly illuminated so that the values of the percentage daylight factor in building spaces can be directly measured. Real skies are a dynamic phenomenon with the movement of the sun along its path and the availability of clouds as well as the conditions of dust, water vapour and other gaseous molecules in the air that affect the level and quality of natural light.

According to Nabil and Mardaljevic (2006), the standard method for daylighting evaluation, which is the daylight factor, is due for replacement with metrics that are founded on absolute values for the luminous quantities predicted over the course of a full year using sun and sky conditions derived from standardised climate files. The move to more realistic measures of daylighting introduces significant levels of additional complexity in both the simulation of luminous quantities and the reduction of the simulation data to readily intelligible metrics. The $\% \mathrm{DF}$, on the other hand, is relatively simple to use and understand.

At present, there is also a more sophisticated way to assess daylight, such as Climate Based Daylight modelling (CBDM), which is used by many international experts. This method should be adopted in future revisions of national standards and regulations for daylighting assessments in buildings. However, this method has yet to be fully developed. Any replacement of \%DF ideally requires international agreement regarding the metrics to be used together with the adoption of a standardised methodology [7]. Furthermore, it is impracticable to express interior day lighting in terms of the obtainable illumination inside a building at any one time because within a few minutes, that figure is liable to change with corresponding changes in the sky's luminance. Therefore, this study upholds and uses the $\% \mathrm{DF}$ as a method to assess daylight performance, in particular, by using fieldwork data under Malaysia's sky conditions.

\section{Malaysia - Location, Climate and the Sky Characteristics}

Malaysia is located in the equatorial region between 1 degree and 7 degrees north latitude and 100 degrees and 120 degrees east longitude. Most towns in Peninsular Malaysia experience high temperatures and humidity throughout the 
year, without remarkable variations. The diurnal temperature range is a minimum of 23 to $27 \mathrm{C}$ and a maximum of 30 to $34 \mathrm{C}$. The average difference is 6.7 to $8.3 \mathrm{C}$, with an annual $\mathrm{RH}$ value ranging from $74 \%$ to $90 \%$ [10]. Malaysian skies are in the category of very cloudy intermediate skies; they are neither overcast nor clear, even though clear skies occasionally occur in the morning hours and overcast ones occur during the rainy monsoon seasons. The average cloud cover, which is measured in oktas, from 0 okta representing a clear sky and 8 representing an overcast sky, has average Malaysian skies in the range of 6.8 oktas from meteorological stations [11].

\section{Illuminance (lux)}

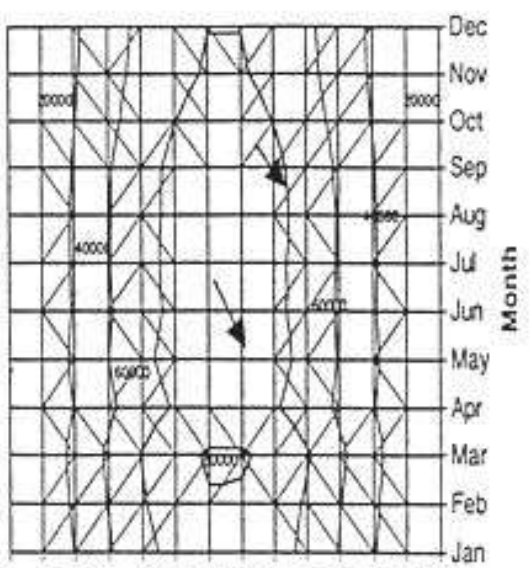

$678 \quad 910111213141516171819$

Time (hrs)

Figure 1. Hourly global illuminance (Ahmed, 2009)

The sky illuminance can be observed in Figure 1, which gives the hourly global illuminance at Klang Valley [12] derived by mathematical methods in all 12 calendar months. It can be observed that the sky illuminance in Malaysia is very bright, reaching a maximum of more than 80,000 lux between 12 noon to $2 \mathrm{pm}$.

Another guideline for sky illuminance is given by BUILDING ENERGY EFFICIENCY TECHNICAL GUIDELINE FOR PASSIVE DESIGN [11], which gives the diffuse daylight availability for the Malaysian climate, with the maximum, minimum and average values in Klux.

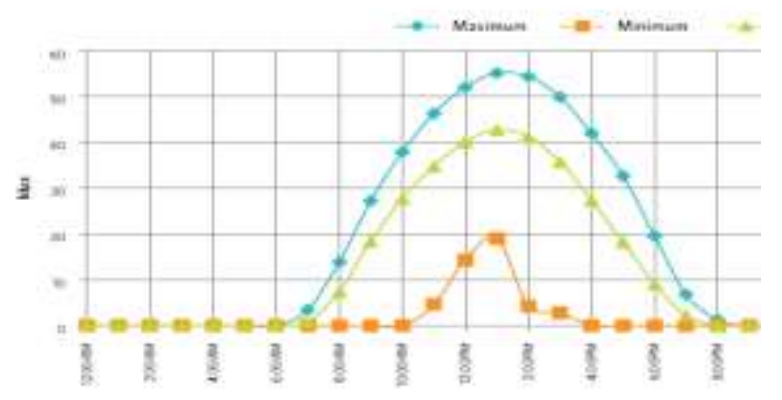

Figure 2. Diffuse daylight availability from weather data (BSEEP, 2014)

Figure 2 by BSEEP (2014) shows that, on average, diffuse light available at 8 am and $6 \mathrm{pm}$ is approximately 12,000 lux and 9,000 lux, respectively. The average peak diffuse light available is 50,000 lux at noon. More interestingly, the average minimum daily light available is above 10,000 lux from the hours of 10 am to $4 \mathrm{pm}$. Because the required lux level in office spaces is between 300 and 400 lux, the chart indicates that only a small fraction of the available outside light from the sky needs to be harvested for indoor use from the hours of 8 am to 6 pm. (BSEEP 2014). For residential rooms or bedrooms that have standards of only 100 to 150 lux, this small fraction can even be smaller.

The sunshine hours, which is an indication of the amount of time during daylight hours that direct light from the sun is received (measured with a sunshine recorder), are 7.0 hours in Bayan Lepas Penang [13]. This means that of the 12 hours of daylight duration experienced yearly in Malaysia, about half is made up of sunshine hours. Sky illuminance during these times is brighter than diffuse illuminance, at times reaching more than 100,000 lux.

\section{Objectives of Study}

This study has the following objectives:

- To investigate the daylighting pattern in similarly designed rooms facing east and west

- To determine how the single point \%DF can be derived simultaneously from both rooms

- To observe the effects of varied window to wall ratios WWRs and window to floor ratios (WFRs) on the $\%$ DF values

- To estimate the approximate level of the natural illumination level of a $1 \% \mathrm{DF}$ as received in a real space under real Malaysian skies.

\section{Iv. Methodology}

A case study building was selected from one of the residential blocks of the Universiti Sains Malaysia campus called Fajar Harapan, which is located in Penang Malaysia. The selected rooms face east and west (Figure 3 ). The rooms measure $2.9 \times 4.43$ metres, with floor area of 12.85 square metres. The window area is 4.43 square metres, which makes up $50 \%$ of the window wall ratio (WWR) and $35 \%$ of the window floor ratio (WFR). With this orientation, the east room obtains some direct sunlight in the morning hours, as does the west room in the afternoon hours; this happens throughout the year with slightly different directions depending on latitude and the altitude of sun. March dates were chosen for this study, as the sun path was perpendicular to the east and west façade orientations. (Figure 3).

To obtain more $\%$ DF readings, the windows were also half covered using polystyrene boards (Figure 6), giving a $25 \%$ WWR and a $17 \%$ WFR. 


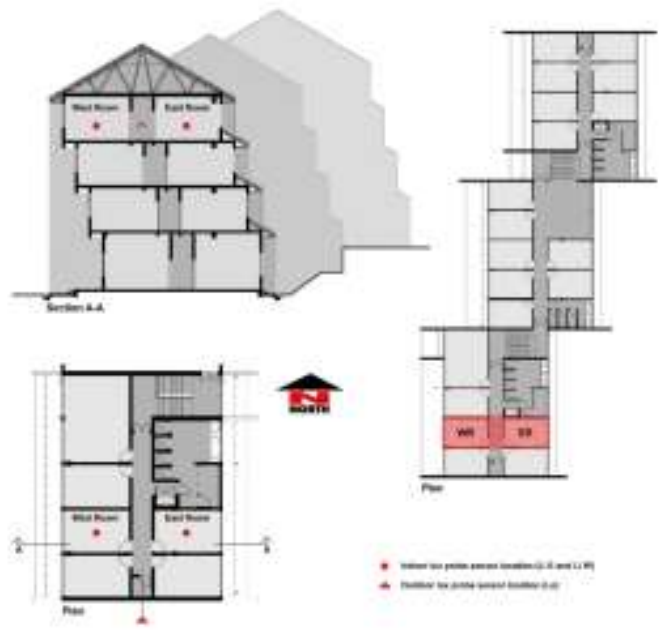

Figure 3. Fajar Harapan: plan and section of the investigated rooms and probe locations

Indoor illumination was taken at the mid-points of the east and west rooms (Ee and Ew) using luxmeter probes located 1 metre above the floor level. Readings were logged every 10 minutes using a data logger simultaneously with an outdoor weatherproof light probe (Eo). Similar techniques were carried out with the window areas half covered (Figure 6). All measurements were carried out in March (7-21 March). March was chosen because the sun path for the locality of Penang is more directly perpendicular to the room's orientation. (Figure 4).

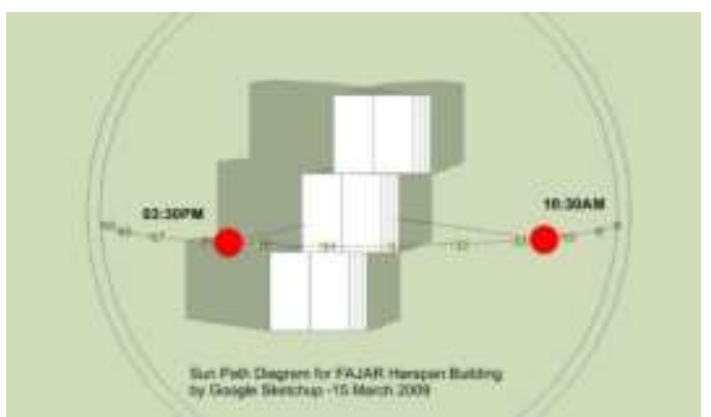

Figure 4. Example of the March sun path for Penang Malaysia) (Google sketchup).

Readings were taken using a BABUC data logger that had three probes connected to it. The first was the indoor lux meter probe at the mid-point of the east room. The second as the indoor lux meter probe at the mid-point of the west room. The third as the outdoor lux meter probe at an unobstructed point outside of the rooms (Figure 3). The indoor probes had a reading range of $0-20,000$ lux, and the outdoor probe was weatherproof, with a reading range of $0-$ 100,000 lux. This experiment was carried out for 12 consecutive days - six days for the original window design of a WWR of $50 \%$ (WFR of $35 \%$ ) and the other six days for a WWR of $25 \%$ (WFR of $17 \%$ ). To avoid the effects of furniture and internal shadings, both rooms were emptied and assigned reflectance factors of cement render on the floors and white paints on all of the walls and ceilings.

The readings from the six consecutive days were graphed to represent a better pattern of the average illumination pattern on March days. From the pattern of illumination in both the east and west rooms, a method to derive \%DF values that excluded the influence of direct sunlight was carried out. The results are shown in the graphs that follow.

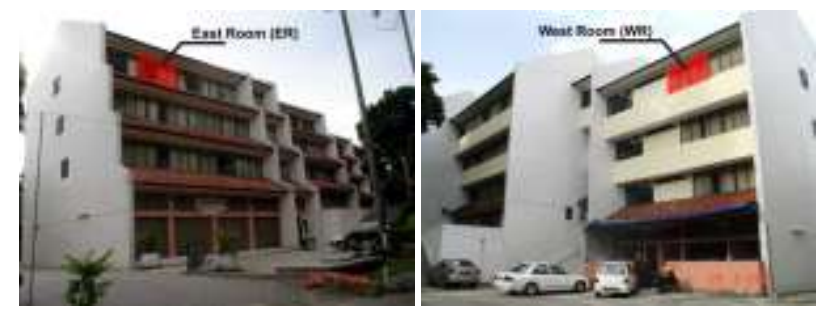

Figure 5.East and west room positions and window shapes.
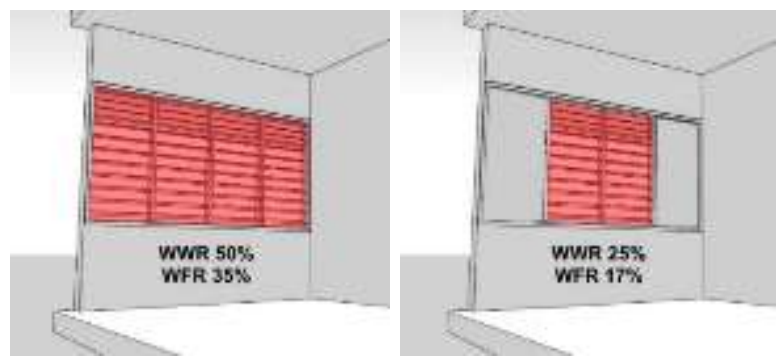

Figure 6. Diagram to show the varied WWRs and WFRs tested.

\section{v. Results and discussion}

Indoor illumination in the east room usually peaked at approximately $9 \mathrm{am}$, while in the west room, it peaked at approximately $5 \mathrm{pm}$; this is an indication of some direct sunlight penetration according to the sun's location and altitude at these particular times. In the fieldwork daylight factor calculations, which are Ee/Eo X 100 and Ew/Eo X 100 , the readings that were observed to be influenced by direct sunlight were disregarded. Readings that were too early in the morning and too late in the evening were also disregarded due to the skies not being uniformly illuminated. Only readings from 10.30 am to $3.30 \mathrm{pm}$ (Figure 7) are considered, as these are the approximate times that direct sunlight does not occur in both rooms. This duration was derived through observation and pattern of data from field work.

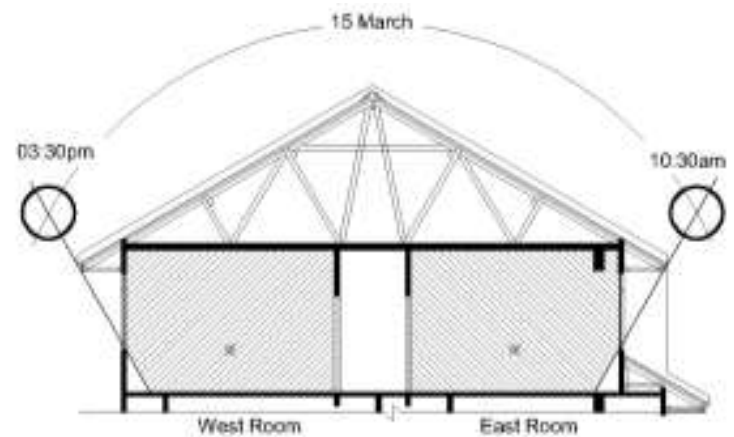

Figure 7. Diagram showing the times during which data were accepted for the $\%$ DF calculation. 
Proc. of The Fifth Intl. Conf. On Advances in Applied Science and Environmental Engineering - ASEE 2016 Copyright (C) Institute of Research Engineers and Doctors, USA .All rights reserved.

ISBN: 978-1-63248-086-6 doi: 10.15224/ 978-1-63248-086-6-29

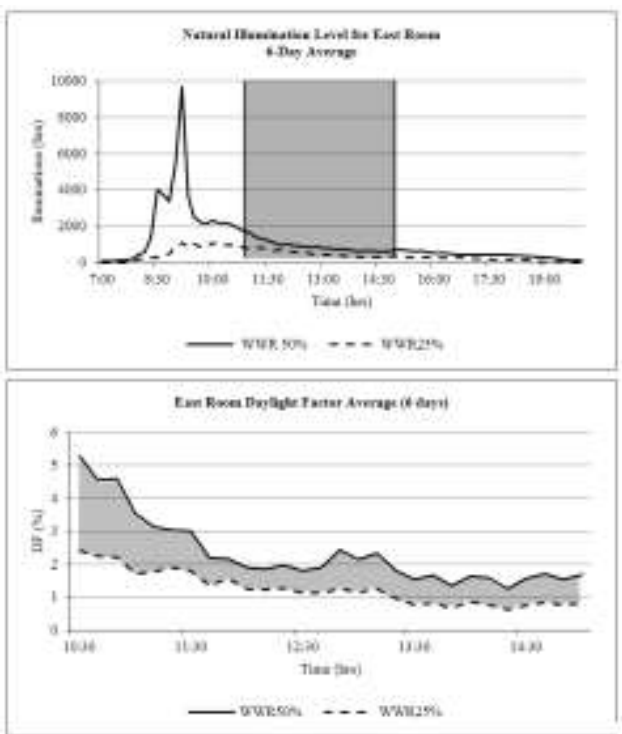

Figure 8. \%DF for the east room (6-Day Average) in both conditions, WWR 50\% and WWR 25\%.

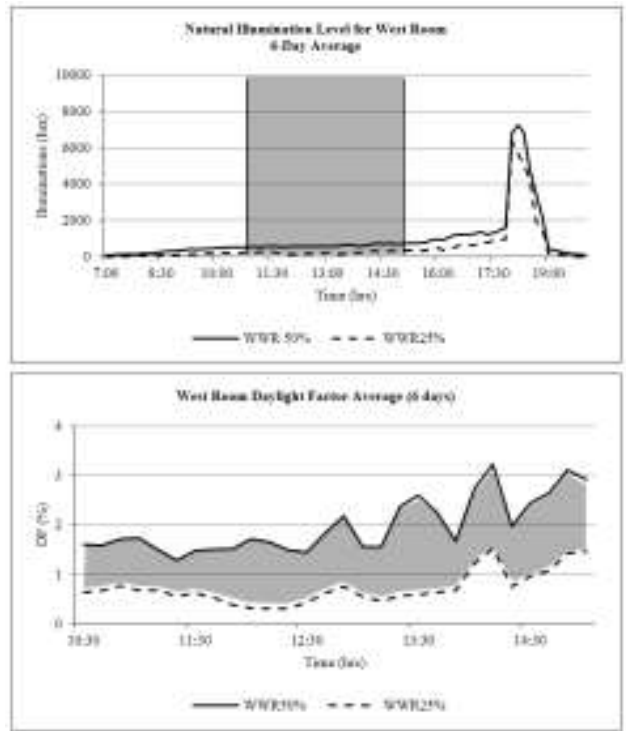

Figure 9. \% DF for the west room (6-Day Average) in both conditions, WWR $50 \%$ and WWR $25 \%$.

\section{vi. Analysis / Summary and Conclusions}

Table 1 below summarises the data collected and depicted in the graphs above. It can be observed that the west room experiences slightly lower average \%DF values than the east room. From the average \%DF values, how bright they translate into the illuminance level in the rooms under Malaysian skies can be observed in the average, max and min Ei data collected. Data on Eo, on the other hand, describe high illumination of the Malaysian skies. In Malaysia, $1 \% \mathrm{DF}$ and even $0.5 \%$ DF may be sufficient for activities in a residential room, such as resting, reading or taking a nap. This range of \%DF comes with illuminance levels between 100 to 200 lux.
TABLE 1. NATURAL ILLUMINATION LEVEL AND THE DAYLIGHT FACTOR.

\begin{tabular}{|c|c|c|c|c|c|c|c|}
\hline \multicolumn{8}{|c|}{ East Room } \\
\hline \multicolumn{8}{|c|}{6 Days $(10: 30 \mathrm{am}-3: 30 \mathrm{pm})$} \\
\hline \multirow[t]{2}{*}{$\begin{array}{l}\text { WWR } \\
\end{array}$} & \multicolumn{3}{|c|}{ Li (lux) } & \multicolumn{3}{|c|}{ Lo (klux) } & $\overline{\mathrm{DF}}(\%)$ \\
\hline & $\min$ & $\max$ & ave & $\min$ & $\max$ & ave & $\min \max$ ave \\
\hline $50 \%$ & 586.67 & 2104.33 & 952.37 & 28.587 & 523.59 & 421.08 & $\begin{array}{lll}1.25 & 5.26 & 2.28\end{array}$ \\
\hline $\begin{array}{c}25 \% \\
(16-21 \mathrm{Mar}) \\
\end{array}$ & 276.33 & 965.33 & 515.39 & 13.699 & 417.14 & 291.12 & $\begin{array}{lll}0.63 & 2.41 & 1.23\end{array}$ \\
\hline \multicolumn{7}{|c|}{ Difference } & $\begin{array}{llll}0.62 & 2.85 & 1.05 \\
\end{array}$ \\
\hline \multicolumn{8}{|c|}{ West Room } \\
\hline \multicolumn{8}{|c|}{6 Days $(10: 30 \mathrm{am}-3: 30 \mathrm{pm})$} \\
\hline \multirow[t]{2}{*}{ WWR } & & $\overline{\mathrm{Li} \text { (lux) }}$ & & & Lo (klux) & & $\mathrm{DF}(\%)$ \\
\hline & $\min$ & $\max$ & ave & $\min$ & $\max$ & ave & $\min \max$ ave \\
\hline $\begin{array}{c}50 \% \\
\text { (10-15 Mar) }\end{array}$ & 508.17 & 742.17 & 612.72 & 28.587 & 523.59 & 421.08 & $1.274 .24 \quad 2.26$ \\
\hline $\begin{array}{c}25 \% \\
(16-21 \text { Mar) }\end{array}$ & 106.17 & 353.83 & 224.85 & 13.699 & 417.14 & 291.12 & $0.28 \quad 1.620 .82$ \\
\hline
\end{tabular}

It is also found that the $\% \mathrm{DF}$ values derived from fieldwork were slightly higher in the east room compared to the west room, with a difference of only $0.02 \%$ in a WWR of $50 \%$ and a $0.41 \%$ difference in a WWR of $25 \%$. This may be due to brighter and clearer eastern skies compared to western skies. Although the measurements were taken simultaneously, the average illumination for the east room was 952 lux for a WWR of 50\% and 515 lux for a WWR of $25 \%$. The illumination levels for the west room were considerably lower, averaging 612 lux for a WWR of $50 \%$ and 224 lux for a WWR of $25 \%$. This is clearly an indication of how skies are never uniformly illuminated and that the orientation of windows does affect the internal illumination levels.

The \%DF comparing a WWR of $50 \%$ to $25 \%$ showed that the values decreased by approximately half in both orientations. A WWR of $25 \%$, with an average \%DF in the $0.8-1.2 \% \mathrm{DF}$ range, may provide a better natural illuminance level for rooms when the WWR $50 \%$ is indicating a higher illumination than necessary for bedrooms.

\section{Acknowledgements}

The authors would like to acknowledge the Malaysian government and University Science Malaysia for funding this research through the fundamental research grant scheme (FRGS).

\section{References}

[1] D. S. Strong, "The Daylight Factor," BRE - The Building Research Establishment. BRE Group, UK, p. 10, 2012.

[2] R. G. Hopkinson, P. Petherbridge, and J. Longmore, Daylighting, 1st ed. London: William Heinemann Ltd., 1966.

[3] H. Voll and E. Seinre, "Cooling demand and daylight in the new Tallinn Town Hall buildings the influence of facade design," vol. 30, pp. 1243-1249, 2012.

[4] J. Du and S. Sharples, "Assessing and predicting average daylight factors of adjoining spaces in atrium buildings under overcast sky," Build. Environ., vol. 46, pp. 2142-2152, 2011.

[5] L. E. Mavromatidis, X. Marsault, and H. Lequay, "Daylight factor 
Proc. of The Fifth Intl. Conf. On Advances in Applied Science and Environmental Engineering - ASEE 2016

Copyright (C) Institute of Research Engineers and Doctors, USA .All rights reserved.

ISBN: 978-1-63248-086-6 doi: 10.15224/ 978-1-63248-086-6-29

estimation at an early design stage to reduce buildings' energy consumption due to artificial lighting: A numerical approach based on Doehlert and Box-Behnken designs," Energy, vol. 65, pp. 488502, 2014.

[6] M. H. Ahmad, D. R. Ossen, and K. A. M. Khaidzir, Methodology in architectural research, 1st ed. Johor, Malaysia: Universiti Teknologi Malaysia, 2008.

[7] J. Mardaljevic, "Climate-Based Daylight Analysis for Residential Buildings," Leicester, 2008.

[8] N. Ibrahim and a. Zain-Ahmed, "Daylight Availability in an Office Interior Due to Various Fenestration Options," 2nd PALENC Conf. 28th AIVC Conf. Build. Low Energy Cool. Adv. Vent. Technol. 21st Century, vol. 1, no. September, pp. 436-440, 2007.

[9] A. Nabil and J. Mardaljevic, "Useful daylight illuminances: A replacement for daylight factors," Energy Build., vol. 38, no. 7, pp. 905-913, 2006.

[10] MMD, "Malaysian Metrological Department," General Climate of Malaysia, 2009. [Online]. Available: http://www.met.gov.my/index.php?option=com_content\&task=view \&id=75\&Itemid=1089. [Accessed: 01-Jan-2009].

[11] BSEEP, "Presentation for the Prime Minister's Green Tech and Climate Change Council Meeting. Realising the 3 Key Benefits of Energy Efficient Buildings," Kuala Lumpur, 2014.

[12] A. Z. Ahmed, "Climate Change, Green Technology and Sustainable Buildings," Selangor, Malaysia, 2009.

[13] A. Abdullah, S. F. S. Fadzil, and N. A. M. Al-Tamimi, "Daylight Illumination Levels in Varied Room Configurations At the View Condominium, Penang, Malaysia," 3rd Int. Conf. Built Environ. Ctries., vol. 1, pp. 434-447, 2009.

About Authors:

$\mid$\begin{tabular}{c|} 
Assoc Prof Dr Sharifah Fairuz Syed \\
Fadzil is currently the Chair of the \\
Architecture Cluster of HBP, USM. \\
Her specialication include daylighting, \\
thermal performance and building \\
simulations
\end{tabular}

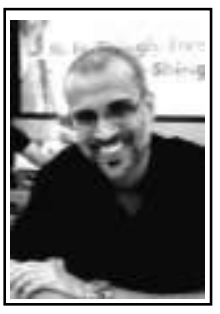

Dr Adel Abdullah

$\mathrm{PhD}$ in daylighting, thermal performance and building simulations

School of Housing, Buildings and

Planning, (HBP)

Universiti Sains Malaysia (USM) 